\title{
Effectiveness and Influencing Factors of Comprehensive Rehabilitation Therapy in Patients with Aneurysmal Subarachnoid Hemorrhage
}

\author{
Xiaoli Wu, Lu Zhang, Yudong Chen, Hanzhi Li, Lingyu Yang, Fei Gao, Yuqi Yang, Xueyan Hu, \\ Changqing Ye, Yuge Zhang, Lei Shan, Lixu Liu, Tong Zhang*
}

Department of Neurorehabilitation, Rehabilitation Medicine of Capital Medical University, China Rehabilitation Research Centre, Beijing, China

Email: ${ }^{\star T o m 611 @ 126 . c o m ~}$

How to cite this paper: Wu, X.L., Zhang, L., Chen, Y.D., Li, H.Z., Yang, L.Y., Gao, F., Yang, Y.Q., Hu, X.Y., Ye, C.Q., Zhang, Y.G., Shan, L., Liu, L.X. and Zhang, T. (2020) Effectiveness and Influencing Factors of Comprehensive Rehabilitation Therapy in Patients with Aneurysmal Subarachnoid Hemorrhage. Journal of Behavioral and Brain Science, 10, 387-399. https://doi.org/10.4236/jbbs.2020.1010024

Received: August 31, 2020

Accepted: October 18, 2020

Published: October 21, 2020

Copyright ( 2020 by author(s) and Scientific Research Publishing Inc. This work is licensed under the Creative Commons Attribution International License (CC BY 4.0).

http://creativecommons.org/licenses/by/4.0/ (c) (i) Open Access

\begin{abstract}
This study aimed to determine the effectiveness of comprehensive rehabilitation for patients with aneurysmal subarachnoid hemorrhage (aSAH) and to explore the factors influencing the prognosis of rehabilitation. This was a retrospective study. Twenty-five patients with aSAH were treated with physical therapy, occupational therapy, speech therapy, cognitive therapy, music therapy, Chinese acupuncture, hyperbaric oxygen, and transcranial magnetic stimulation. The general data of all patients were collected, and the functional scores at admission were compared with those at discharge. The Mini Mental State Examination, Fugl-Meyer Assessment Scale (FMAS) for motor and balance assessment, Holden Functional Ambulation Classification (FAC), modified Rankin Scale, National Institute of Health Stroke Scale, Modified Barthel Index for activities of daily living (ADL), and Glasgow Outcome Scale were significantly improved among 25 patients with aSAH after 1 month of comprehensive rehabilitation training. Hydrocephalus was an independent factor of the ability to perform ADLs (odds ratio, 0.29 ; 95\% confidence interval, 2.03. 3.15; $\mathrm{p}=0.000$ ). The improvement of ADLs in aSAH patients was not related to sex, surgical method, aneurysm location, age, or smoking status. Comprehensive and professional rehabilitation is effective for the cognition, movement, walking, ADLs, and functional prognosis of patients with aSAH, while early hydrocephalus may be a risk factor for poor ADLs.
\end{abstract}

\section{Keywords}

Aneurysmal Subarachnoid Hemorrhage, Rehabilitation Therapy, Prognosis, 
Activities of Daily Living

\section{Introduction}

Aneurysmal subarachnoid hemorrhage (aSAH) is a disease associated with high mortality and disability rates [1]. Although the management of aSAH has improved significantly in recent years, at least $50 \%$ of the patients are left with permanent dysfunction and cognitive impairment, and $>90 \%$ of the patients have decreased quality of life [2] [3] [4]. After aSAH, patients undergo complex and individualized rehabilitation due to differing aneurysm locations and surgical methods, as well as different neurological complications such as rebleeding, hydrocephalus, epileptic seizures, and delayed cerebral ischemia (DCI) [4] [5] [6]. In particular, secondary changes, such as brain edema and acute cerebral vasospasm (CVS) caused by the subarachnoid space, are the key factors leading to high mortality and disability rates [2] [7] [8] [9].

Patients with aSAH usually experience hemiplegia, cognitive dysfunction, emotional behavior disorder, speech dysfunction, and/or urinary incontinence after treatment in the acute phase. Previous studies have reported that, three months after aSAH, patients had significant functional limitations in terms of body movement, cognition, and emotion; these functional limitations, especially cognitive impairment, significantly affected the patients' activities of daily living at discharge and the probability of returning to work [2] [3] [10] [11] [12]. Many researchers have emphasized the importance of early and comprehensive professional rehabilitation, which can improve patients' quality of life [13] [14] [15]. However, most studies have focused on the efficacy and safety of early rehabilitation for patients with acute subarachnoid hemorrhage and on the effectiveness of a specific rehabilitation method [9] [16] [17] [18]. Prospective studies with large samples on the rehabilitation of patients with aSAH are lacking.

Some studies have shown that the prognosis in the acute stage is not necessarily consistent with the long-term functional results. Although the goal of treatment in the acute stage is to minimize neurological complications such as hydrocephalus and delayed cerebral infarction, it does not always improve long-term functional outcomes [19] [20]. Over time, the participation of functionally independent aSAH patients has improved; however, a third of patients still experience one or more participation restrictions after 1 year, especially those with depression. Therefore, it is important to further explore the factors affecting long-term prognosis. Wong et al. found that delayed cerebral infarction was an independent risk factor for cognitive deficits at 1 year [9], while early cognitive impairment is considered to be an important factor affecting the prognosis of rehabilitation, especially visual spatial memory defects and language defects [21]. Another study confirmed that race, education, severe hunt grade, hydrocephalus, and DCI are predictive factors for poor quality of life 
(QOL) [2].

This study retrospectively analyzed the data of patients with aSAH in the hospital's neurorehabilitation department to clarify the effects of comprehensive rehabilitation on cognition, hemiplegia, and activities of daily living (ADLs) and to analyze the risk factors that may affect rehabilitation.

\section{Methods}

\subsection{Design}

We conducted a retrospective study to evaluate the effects of comprehensive rehabilitation on patients with aSAH. We also aimed to explore whether the location of the aneurysm, surgical method, age, smoking status, degree of dysfunction, and neurological complications at admission affect the prognosis of rehabilitation. This study was approved by the Ethical Committee of the China Rehabilitation Research Centre and conducted in accordance with the Declaration of Helsinki.

\subsection{Setting and Participants}

The data of patients with aSAH admitted to the neurorehabilitation department of the China Rehabilitation Research Center between January 2018 and February 2020 were reviewed using a medical workstation. The medical records of all patients were obtained from the electronic medical record system (EMR, HIS system, 5.6 edition). All patients received comprehensive rehabilitation treatment. The diagnosis of aSAH was based on computed tomography (CT) findings, and patients were excluded if they did not receive rehabilitation treatment or were hospitalized for less than 1 month. Patients with aSAH caused by traumatic or arteriovenous malformations or unknown causes were also excluded from the study. The aSAH diagnosis was confirmed using intra-arterial digital subtraction angiography (DSA) or CT angiography (CTA). DCI is defined as a new cerebral infarction identified on CT scans after SAH [22]. Cerebral hemorrhage was diagnosed via $\mathrm{CT}$ at onset or after operation.

\subsection{Evaluation of Function and Outcomes}

The general information, course of disease, limb paralysis, state of consciousness, and functional scores at admission and discharge were extracted from the medical records of the patients who met the study criteria. The patients' cognitive function, limb motor function, balancing function, walking ability, swallowing ability, ability to perform ADLs, and outcome were assessed using the Mini Mental State Examination (MMSE) [23], Fugl-Meyer Assessment Scale (FMAS) for motor and balance assessment [24], Holden Functional Ambulation Classification (FAC) [25], modified Rankin Scale (mRS) [26] [27], National Institute of Health Stroke Scale (NIHSS) [28] [29], Modified Barthel Index (MBI) [30] [31], Glasgow Outcome Scale (GOS) [32] [33], and World Federation of Neurosurgical Societies Grading System of Subarachnoid He- 
morrhage (WFNS-SAH) [34] [35]. All patients were assessed at admission and one month later.

\subsection{Comprehensive Rehabilitation Program}

According to individual functional limitations, all patients received training using a combination of multiple rehabilitation methods. In addition to drug therapy for improving cognition, preventing and controlling epilepsy, controlling blood pressure, and improving mood, the specific rehabilitation training programs used are shown in Table 1.

\subsection{Data Analysis}

Microsoft Excel (Microsoft Office 2010, Microsoft Corporation, China) was used for data collection and recording. Categorical data are given as numbers (percentages) unless otherwise specified. The numerical data are given as medians and standard deviations (SDs). The treatment effect was determined by comparing the scores upon admission and after one month of comprehensive rehabilitation using the Wilcoxon signed-rank test. The ratios of mRS and GOS scores before and after treatment were compared using the chi-square test. The chi-square test was also used to analyze factors (gender, age, course of disease, aneurysm location, operation mode, hypertension, delayed cerebral infarction) influencing patients' ability to perform ADLs, and multivariate logistic stepwise regression analysis was performed. Statistical analyses were performed using the SPSS statistical package (version 23.0; SPSS Inc.), and p-values $>0.05$ were considered statistically significant.

\section{Results}

\subsection{Demographic and Clinical Characteristics.}

Between January 2018 and February 2020, 45 patients were admitted to the

Table 1. Summary of comprehensive rehabilitation methods.

\begin{tabular}{|c|c|c|c|c|c|c|}
\hline Aim & $\begin{array}{l}\text { Movement and } \\
\text { transfer ability }\end{array}$ & cognitive function & Dysphagia & $\begin{array}{l}\text { language } \\
\text { function }\end{array}$ & $\mathrm{ADL}$ & Other \\
\hline \multirow[b]{3}{*}{ Item } & Physical therapy & $\begin{array}{c}\text { Computer aided } \\
\text { cognitive function } \\
\text { training }\end{array}$ & $\begin{array}{c}\text { Swallowing } \\
\text { training }\end{array}$ & $\begin{array}{c}\text { Transcranial magnetic } \\
\text { stimulation }\end{array}$ & $\begin{array}{l}\text { Occupational } \\
\text { therapy }\end{array}$ & $\begin{array}{c}\text { Hyperbaric } \\
\text { oxygen }\end{array}$ \\
\hline & $\begin{array}{l}\text { Occupational } \\
\text { therapy }\end{array}$ & $\begin{array}{l}\text { Transcranial } \\
\text { magnetic } \\
\text { stimulation }\end{array}$ & $\begin{array}{c}\text { Electrical } \\
\text { stimulation } \\
\text { of swallowing }\end{array}$ & Speech therapy & $\begin{array}{c}\text { Rehabilitation } \\
\text { nursing } \\
\text { guidance }\end{array}$ & $\begin{array}{l}\text { Chinese } \\
\text { acupuncture }\end{array}$ \\
\hline & $\begin{array}{l}\text { Sling Exercise } \\
\text { Therapy }\end{array}$ & $\begin{array}{c}\text { Neuromusical } \\
\text { therapy (Music } \\
\text { cognitive orientation } \\
\text { training)) }\end{array}$ & $\begin{array}{c}\text { ice } \\
\text { stimulation }\end{array}$ & $\begin{array}{l}\text { Neuromusical } \\
\text { therapy (Melodic } \\
\text { tonality therapy; } \\
\text { Therapeutic singing) }\end{array}$ & $\begin{array}{l}\text { propaganda } \\
\text { and education }\end{array}$ & $\begin{array}{c}\text { Physical factor } \\
\text { therapy }\end{array}$ \\
\hline
\end{tabular}


neurorehabilitation department with a diagnosis of aSAH. Twenty patients were excluded because the SAH was determined to be caused by arteriovenous malformation $(n=3)$, trauma $(n=10)$, or unknown etiology/other causes $(n=7)$. The majority of patients in this study were male (56\%), and the mean age was 56.84 years $(\mathrm{SD}=10.9)$. At admission, two patients were in a state of minimal consciousness, and the other patients were conscious. Demographic and clinical characteristics are summarized in Table 2.

Table 2. Demographic and clinical characteristics of aSAH patients $(\mathrm{N}=25)$.

\begin{tabular}{|c|c|c|c|}
\hline Characteristic & & \multicolumn{2}{|c|}{ Value } \\
\hline Male & 14 & \multicolumn{2}{|c|}{$56 \%$} \\
\hline Female & 11 & \multicolumn{2}{|c|}{$44 \%$} \\
\hline Age (years), $\bar{x}+S D$ & \multicolumn{3}{|c|}{$56.84 \pm 10.9$} \\
\hline Course of disease (days) & $14-710$ & \multicolumn{2}{|c|}{$130.84 \pm 149.13$} \\
\hline $\begin{array}{l}\text { Years of education, } \\
\bar{x}+S D \quad \text { (years) }\end{array}$ & $0-22$ & \multicolumn{2}{|c|}{$11.68 \pm 5.79$} \\
\hline Smoking & 8 & \multicolumn{2}{|c|}{$32 \%$} \\
\hline Hypertension & 17 & \multicolumn{2}{|c|}{$68 \%$} \\
\hline \multirow{4}{*}{ Paralysis of limbs } & Right limb & 5 & $20 \%$ \\
\hline & Left limb & 5 & $20 \%$ \\
\hline & Bilateral limbs & 14 & $56 \%$ \\
\hline & No paralysis & 1 & $4 \%$ \\
\hline \multirow{2}{*}{$\begin{array}{l}\text { Type of aneurysm } \\
\text { treatment }\end{array}$} & Endovascular coil embolization & 18 & $72 \%$ \\
\hline & Surgical clip ligation & 7 & $28 \%$ \\
\hline \multirow{2}{*}{ Location of aneurysm } & Anterior circulation & 20 & $80 \%$ \\
\hline & Posterior circulation & 5 & $20 \%$ \\
\hline \multirow{5}{*}{ Clinical characteristics } & Disturbance of consciousness & 2 & $8 \%$ \\
\hline & Ventriculoperitoneal shunt & 9 & $36 \%$ \\
\hline & Decompressive hemicraniectomy & 11 & $44 \%$ \\
\hline & Delayed cerebral infarction & 15 & $60 \%$ \\
\hline & $\begin{array}{l}\text { With cerebral parenchymal } \\
\text { hemorrhage }\end{array}$ & 11 & $44 \%$ \\
\hline \multirow{5}{*}{ WFNS-SAH } & I grade & 1 & $4 \%$ \\
\hline & II grade & 1 & $4 \%$ \\
\hline & III grade & 0 & \\
\hline & IV grade & 6 & $24 \%$ \\
\hline & $\mathrm{V}$ grade & 17 & $68 \%$ \\
\hline \multirow{6}{*}{$\mathrm{mRS}$} & 0 grade & 0 & \\
\hline & 1 grade & 0 & \\
\hline & 2 grade & 0 & \\
\hline & 3 grade & 1 & $4 \%$ \\
\hline & 4 grade & 14 & $56 \%$ \\
\hline & 5 grade & 10 & $40 \%$ \\
\hline
\end{tabular}

Abbreviations: aneurysmal subarachnoid hemorrhage (aSAH); standard deviation (SD); World Federation of Neurosurgical Societies Grading System of Subarachnoid Hemorrhage (WFNS-SAH); modified Rankin Scale (mRS). 


\subsection{Functional Outcomes}

After one month of comprehensive rehabilitation training, the FMAS for motor and balance assessment, MMSE score of cognitive function, MBI of ADLs, FAC, NIHSS, mRS, and GOS were significantly improved in 25 patients (Table 3 ). This suggests comprehensive rehabilitation training is effective for patients with aSAH.

Table 3. Changes in clinical scores of patients with aSAH before and after 1 month of rehabilitation treatment.

\begin{tabular}{|c|c|c|c|c|c|}
\hline \multicolumn{2}{|c|}{ Rating scales } & At admission & After 1 month & $\mathrm{Z} / \chi^{2}$ & $\mathrm{P}$ \\
\hline \multicolumn{2}{|c|}{ MMSE } & $5.48 \pm 9.39$ & $8.68 \pm 10.70$ & -3.068 & 0.002 \\
\hline \multicolumn{2}{|c|}{ FMAS for motor } & $38.40 \pm 32.703$ & $44.36 \pm 33.581$ & -3.642 & 0.000 \\
\hline \multicolumn{2}{|c|}{ FMAS for balance } & $4.40 \pm 4.031$ & $6.04 \pm 4.383$ & -3.758 & 0.000 \\
\hline \multicolumn{2}{|c|}{ NIHSS } & $11.280 \pm 5.136$ & $10.6 \pm 5.408$ & -2.179 & 0.029 \\
\hline \multicolumn{2}{|c|}{ MBI } & $28.2 \pm 27.223$ & $40.00 \pm 27.950$ & -3.841 & 0.000 \\
\hline \multirow{7}{*}{$\mathrm{mRS}$} & 0 grade & 0 & 0 & \multirow{7}{*}{9.632} & \multirow{7}{*}{0.047} \\
\hline & 1 grade & 0 & 0 & & \\
\hline & 2 grade & 0 & 0 & & \\
\hline & 3 grade & 1 & 7 & & \\
\hline & 4 grade & 13 & 14 & & \\
\hline & 5 grade & 9 & 2 & & \\
\hline & 6 grade & 0 & 0 & & \\
\hline \multirow{5}{*}{ GOS } & 1 grade & 0 & 0 & \multirow{5}{*}{11.536} & \multirow{5}{*}{0.003} \\
\hline & 2 grade & 4 & 2 & & \\
\hline & 3 grade & 21 & 21 & & \\
\hline & 4 grade & 0 & 2 & & \\
\hline & 5 grade & 0 & 0 & & \\
\hline \multirow{6}{*}{ FAC } & 0 grade & 17 & 12 & \multirow{6}{*}{50.314} & \multirow{6}{*}{0.000} \\
\hline & 1 grade & 3 & 5 & & \\
\hline & 2 grade & 3 & 5 & & \\
\hline & 3 grade & 0 & 0 & & \\
\hline & 4 grade & 1 & 2 & & \\
\hline & 5 grade & 1 & 1 & & \\
\hline \multirow{7}{*}{$\begin{array}{l}\text { Classification of } \\
\text { ingestion and } \\
\text { swallowing } \\
\text { function }\end{array}$} & 7 grade & 13 & 14 & \multirow{7}{*}{77.289} & \multirow{7}{*}{0.000} \\
\hline & 6 grade & 3 & 1 & & \\
\hline & 5 grade & 1 & 1 & & \\
\hline & 4 grade & 2 & 5 & & \\
\hline & 3 grade & 3 & 2 & & \\
\hline & 2 grade & 0 & 0 & & \\
\hline & 1 grade & 3 & 2 & & \\
\hline
\end{tabular}

Abbreviations: Mini Mental State Examination (MMSE); Fugl-Meyer Assessment Scale (FMAS); National Institute of Health Stroke Scale (NIHSS); Modified Barthel Index (MBI); modified Rankin Scale (mRS); Glasgow Outcome Scale (GOS); Holden Functional Ambulation Classification (FAC). 


\subsection{Risk Factors}

The factors affecting improvement of ADL in patients with aSAH are shown in Table 4. The chi-square test revealed significant differences in smoking $(\mathrm{P}=$ 0.032 ) and hydrocephalus $(\mathrm{p}<0.001)$, but there were no significant differences in sex, age, operation mode, aneurysm location, education, DCI, or WFNS-SAH between the two groups $(\mathrm{p}>0.05)$. Considering the possible interactions between factors, multivariate logistic stepwise regression was used to screen variables. Hydrocephalus was an independent factor for the ability to perform ADLs (OR, 0.29; 95\% confidence interval [CI], 2.03 - 3.15; p = 0.000). Improvement in ADLs was not related to sex, surgical method, aneurysm location, age, or smoking status.

Table 4. Factors affecting activities of daily living.

\begin{tabular}{|c|c|c|c|c|c|}
\hline Items & & $\begin{array}{c}\mathrm{MBI} \leq 35 \\
\text { (n) }\end{array}$ & $\begin{array}{c}\mathrm{MBI}>35 \\
(\mathrm{n})\end{array}$ & $\chi^{2}$ & $\mathrm{P}$ \\
\hline \multirow{2}{*}{ Sex } & Female & 3 & 8 & \multirow{2}{*}{2.231} & \multirow{2}{*}{0.135} \\
\hline & Male & 8 & 6 & & \\
\hline \multirow{3}{*}{ Age (years) } & $\leq 50$ & 3 & 3 & \multirow{2}{*}{0.115} & \multirow{2}{*}{0.734} \\
\hline & $>50$ & 8 & 11 & & \\
\hline & 0 & 0 & 3 & \multirow{3}{*}{3.423} & \multirow{3}{*}{0.181} \\
\hline \multirow[t]{2}{*}{ Years of education } & $\leq 12$ & 7 & 5 & & \\
\hline & $>12$ & 4 & 6 & & \\
\hline \multirow{2}{*}{$\begin{array}{l}\text { Method of } \\
\text { treatment }\end{array}$} & Clipping & 3 & 4 & \multirow{2}{*}{0.005} & \multirow{2}{*}{0.943} \\
\hline & Coiling & 8 & 10 & & \\
\hline \multirow{2}{*}{$\begin{array}{c}\text { Location of } \\
\text { aneurysm }\end{array}$} & Anterior circulation & 9 & 11 & \multirow{2}{*}{0.041} & \multirow{2}{*}{0.840} \\
\hline & Posterior circulation & 2 & 3 & & \\
\hline \multirow{2}{*}{ Hypertension } & Yes & 9 & 8 & \multirow{2}{*}{1.724} & \multirow{2}{*}{0.189} \\
\hline & No & 2 & 6 & & \\
\hline \multirow{2}{*}{ Smoking } & Yes & 6 & 2 & \multirow{2}{*}{4.588} & \multirow{2}{*}{0.032} \\
\hline & No & 5 & 12 & & \\
\hline \multirow{2}{*}{ Course of disease } & $\leq 6$ month & 8 & 11 & \multirow{2}{*}{0.115} & \multirow{2}{*}{0.734} \\
\hline & $>6$ month & 3 & 3 & & \\
\hline \multirow{2}{*}{ DCI } & Yes & 7 & 8 & \multirow{2}{*}{0.108} & \multirow{2}{*}{0.742} \\
\hline & No & 4 & 6 & & \\
\hline \multirow{2}{*}{ Hydrocephalus } & Yes & 8 & 1 & \multirow{2}{*}{11.5} & \multirow{2}{*}{0.001} \\
\hline & No & 3 & 13 & & \\
\hline \multirow{4}{*}{ WFNS-SAH } & 1 grade & 1 & 0 & \multirow{4}{*}{4.429} & \multirow{4}{*}{0.219} \\
\hline & 2 grade & 0 & 1 & & \\
\hline & 4 grade & 1 & 5 & & \\
\hline & 5 grade & 9 & 8 & & \\
\hline
\end{tabular}

Abbreviations: Modified Barthel Index (MBI); delayed cerebral ischemia (DCI); World Federation of Neurosurgical Societies Grading System of Subarachnoid Hemorrhage (WFNS-SAH). 


\section{Discussion}

It is accepted that aSAH leads to dysfunction and decline of a patient's ability to perform ADLs due to complications with cerebral parenchyma hemorrhage, DCI, hydrocephalus, and so on. Therefore, although many rehabilitation studies have been published on stroke, there are few on the rehabilitation of patients with SAH, especially aSAH. In this study, we compared function scores and ADLs at admission with those after 1 month of rehabilitation and found that comprehensive rehabilitation significantly improved cognitive and motor function, prognosis, and ADLs. Though there were only 25 patients in this study, the effectiveness of rehabilitation can still be seen after subgroup analysis according to aneurysm location, surgical intervention, and WFNS-SAH at onset. To further clarify the factors affecting the prognosis of rehabilitation, future studies with larger samples are needed.

In 2002, researchers investigated the prognosis of aSAH patients 3 months after onset. Sixty-one patients were selected, and their Extended Glasgow Outcome Scale (GOSE) and functional status examination scores were evaluated. The results showed that, in almost all aspects of life, including physical activity, cognition, and emotion, scores decreased in patients with aSAH after three months, and the ADLs of most patients decreased significantly. This demonstrates that proper rehabilitation intervention is needed, and that family education and guidance can improve these patients' QOL [10]. Before that study, researchers in Japan investigated the return-to-work rate of middle-aged patients with aSAH. They found that patients with Hunt scores of 2 or below were more likely to return to work than those with Hunt scores of 3 or above. The gender, occupation, employer, and socio-economic background of patients were shown to affect return-to-work probability [11]. In 2014, Maeshima et al. reported a rare case of unilateral hippocampal injury caused by a ruptured posterior cerebral aneurysm [36]. Although the condition was stable after acute treatment and the instantaneous and long-term memory were almost completely preserved, the patient's short-term memory was moderately damaged. The authors believed that, after 10 weeks of cognitive-function evaluation and treatment, the patient's cognitive function and social participation abilities had improved; they put forth that dynamic functional imaging can be used to explore the presence of brain-function remodeling. These studies suggest that focusing on the rehabilitation of aSAH (especially the cognitive, motor, and ADL aspects) can better improve the ability of patients to return to society.

A Japanese study reviewed the impact of neuropsychological damage on motor function in patients with aSAH and emphasized that treatment in the acute phase is lifesaving. However, many patients with aSAH experience long-term functional impairment, such as cognitive impairment or emotional disorder. It is believed that rehabilitation treatment can improve brain injury after aSAH [15]. However, the available literature on the rehabilitation of patients with aSAH is comprised of mostly case reports and studies focusing on rehabilitation in the 
acute stage; the findings suggest that early rehabilitation is safe and effective, and moderate rehabilitation can improve depression, cognition, and language-learning ability [13] [14] [16] [17] [37]. However, there are few studies on rehabilitation in the convalescent period.

There was one study published on rehabilitation combined with ventriculoperitoneal shunt for the treatment of chronic normal intracranial pressure hydrocephalus after SAH [38] [39]. During the course of rehabilitation, 39 patients were diagnosed with normal intracranial pressure hydrocephalus. Among them, 24 patients underwent ventriculoperitoneal shunt surgery and 15 patients did not undergo shunt placement. After 1 and 6 months of rehabilitation treatment, the MBI and MMSE scores were evaluated. The results suggest that rehabilitation therapy alone cannot improve the symptoms of chronic normal intracranial pressure hydrocephalus, but when combined with ventriculoperitoneal shunt, they can significantly improve cognitive function and ADL ability. It should be noted, however, that the study had no specific descriptions of rehabilitation intervention, rehabilitation dose, or other details.

A prospective study was conducted to analyze the forms of cognitive impairment among patients with aSAH and the influencing factors of cognitive-function prognosis, such as age, NIHSS, mRS, and BDI [12]. Through a 26-month follow-up study, it was found that, in addition to the age of onset, DCI was the main independent risk factor for cognitive impairment one year after aSAH. No correlation was noted between the location of aneurysm and WFNS-SAH upon admission. Subsequently, another prospective cohort study was conducted to analyze the risk factors of poor quality of life in patients with aSAH [2]. The researchers found that non-white race, low education level, depression, high Hunt grade, and DCI were predictors of poor QOL one year after onset. Poor QOL was associated with age, secondary hydrocephalus, secondary pneumonia, and sepsis. The article also mentioned that $91 \%$ of patients with poor QOL could not return to work, and that these patients only received exercise therapy; little attention was paid to the rehabilitation of cognitive or emotional behavior. When taken together, these two studies indicate that a third of patients with aSAH have poor QOL after one year and that DCI is the most important influencing factor for poor prognosis [2] [12]. Early intervention rehabilitation and attention to cognitive and emotional disorders can help patients achieve higher QOL. Although our study was a retrospective analysis and the number of cases was relatively small, we have shown that comprehensive rehabilitation has certain effects, regardless of the degree of illness. It not only improves motor function, but also improves cognition, thus improving ADLs and reducing the burden of family care. However, we found smoking and hydrocephalus to be impact factors for ADL ability, especially in the further multiple regression analysis, suggesting that only hydrocephalus is an independent risk factor for poor ADL ability. In addition to the small sample size, this may be related to the relatively serious conditions of the included patients (GOS of 3 or 
below, mRS of $4-5)$.

\section{Limitations of the Study}

This study had several limitations. It was a retrospective analysis, and the sample size was relatively small. Due to this small sample size, the significance of statistical difference might be insufficient in the subgroup analysis for risk factors. Second, the WFNS-SAH of the hospitalized patients analyzed in this study was 4 or 5 , the GOS was concentrated in grade 3 , and mRS was 4 or above, which does not represent the rehabilitation treatment of all patient levels. Third, the rehabilitation treatment used in this study was comprehensive, and some suitable treatment methods may not have been included due to various factors of the patients or their families; this may not fully reflect the best effect of rehabilitation.

\section{Conclusion}

The results of this retrospective study suggest that comprehensive rehabilitation therapy is effective for patients with aSAH. Regardless of the location of the aneurysm, the method of surgical intervention, and the degree of illness at admission, the cognitive function, motor function, and activities of daily living are improved after rehabilitation treatment. Therefore, it is suggested that patients with aSAH should receive comprehensive and professional rehabilitation as early as possible, which is conducive to the improvement of patients' function and ability of daily life.

\section{Acknowledgements}

We would like to thank all of our colleagues in the Neurorehabilitation Department of China Rehabilitation Research Center for their help in the project.

\section{Conflicts of Interest}

The authors declare no conflicts of interest regarding the publication of this paper.

\section{References}

[1] Ingall, T., Asplund, K., Mähönen, M. and Bonita, R. (2000) A Multinational Comparison of Subarachnoid Hemorrhage Epidemiology in the WHO MONICA Stoke Study. Stroke, 31, 1054-1061. https://doi.org/10.1161/01.STR.31.5.1054

[2] Taufique, Z., May, T., Meyers, E., Falo, C., Mayer, S.A., Agarwal, S., et al. (2016) Predictors of Poor Quality of Life 1 Year after Subarachnoid Hemorrhage. Neurosurgery, 78, 256-264. https://doi.org/10.1227/NEU.0000000000001042

[3] Hop, J.W., Rinkel, G.J., Algra, A. and Van Gijn, J. (1998) Quality of Life in Patients and Partners after Aneurysmal Subarachnoid Hemorrhage. Stroke, 29, 798-804. https://doi.org/10.1161/01.STR.29.4.798

[4] Hutter, B.O., Kreitsehmann-Andermahr, I. and Gilsbach, J.M. (2001) Health-Related Quality of Life after Aneurysmal Subarachnoid Hemorrhage: Impacts of Bleeding Severity, Computerized Tomography Finding, Surgery, Vasospasm, and Neurological 
Grade. Journal of Neurosurgery, 94, 241-251. https://doi.org/10.3171/jns.2001.94.2.0241

[5] Diringer, M.N. (2009) Management of Aneurysmal Subarachnoid Hemorrhage. Critical Care Medicine, 37, 432-440. https://doi.org/10.1097/CCM.0b013e318195865a

[6] Crowley, R.W., Medel, R., Dumont, A.S., Ilodigwe, D., Kassell, N.F., Mayer, S.A., et al. (2011) Angiographic Vasospasm Is Strongly Correlated with Cerebral Infarction after Subarachnoid Hemorrhage. Stroke, 42, 919-923. https://doi.org/10.1161/STROKEAHA.110.597005

[7] Harmsen, W.J., Ribbers, G.M., Zegers, B., Sneekes, E.M., Praet, S.F.E., Heijenbrok-Kal, M.H., et al. (2017) Impaired Muscle Strength May Contribute to Fatigue in Patients with Aneurysmal Subarachnoid Hemorrhage. International Journal of Rehabilitation Research, 40, 29-36.

https://doi.org/10.1097/MRR.0000000000000197

[8] Al-Khindi, T., Macdonald R.L. and Schweizer, T.A. (2010) Cognitive and Functional Outcome after Aneurysmal Subarachnoid Hemorrhage. Stroke, 41, e519. https://doi.org/10.1161/STROKEAHA.110.581975

[9] Wong, G.K.C., Wong, A., Mok, V., Wong, A. and Poon, W.S. (2010) Natural History and Medical Treatment of Cognitive Dysfunction after Spontaneous Subarachnoid Hemorrhage: Review of Current Literature with Respect to Aneurysm Treatment. Journal of the Neurological Sciences, 299, 5-8. https://doi.org/10.1016/j.jns.2010.08.059

[10] Kirkness, C.J., Thompson, J.M., Ricker, B.A., Buzaitis, A., Newell, D.W., Dikmen, S., et al. (2002) The Impact of Aneurysmal Subarachnoid Hemorrhage on Functional Outcome. Journal of Neuroscience Nursing, 34, 134-141. https://doi.org/10.1097/01376517-200206000-00006

[11] Nishino, A., Sakurai, Y., Tsuji, I., Arai, H., Uenohara, H., Suzuki, S., et al. (1999) Resumption of Work after Aneurysmal Subarachnoid Hemorrhage in Middle-Aged Japanese Patients. Journal of Neurosurgery, 90, 59-64. https://doi.org/10.3171/jns.1999.90.1.0059

[12] Wong, G.K., Lam, S.W., Ngai, K., Wong, A., Siu, D., Poon, W.S., et al. (2013) Cognitive Domain Deficits in Patients with Aneurysmal Subarachnoid Haemorrhage at 1 Year. Journal of Neurology, Neurosurgery and Psychiatry, 84, 1054-1058. https://doi.org/10.1136/jnnp-2012-304517

[13] Olkowski, B.F., Devine, M.A., Slotnick, L.E., Veznedaroglu, E., Liebman, K.M., Arcaro, M.L., et al. (2012) Safety and Feasibility of an Early Mobilization Program for Patients with Aneurysmal Subarachnoid Hemorrhage. Physical Therapy, 2, 208-215. https://doi.org/10.2522/ptj.20110334

[14] Colledge, F., Brand, S., Pühse, U., Holsboer-Trachsler, E., Zimmerer, S., Schleith, R., et al. (2017) A Twelve-Week Moderate Exercise Programme Improved Symptoms of Depression, Insomnia, and Verbal Learning in Post-Aneurysmal Subarachnoid Haemorrhage Patients: A Comparison with Meningioma Patients and Healthy Controls. Neuropsychobiology, 76, 59-71. https://doi.org/10.1159/000486903

[15] Korzetkowska, K.J., Polityńska, B., Grajdziadek, M., et al. (2010) Rehabilitacja Pacjentów po Krwawieniu Podpajeczynówkowym z Peknietego Tetniaka Wewnatrzczaszkowego [Rehabilitation of Patients Following Subarachnoid Haemorrhage as a Result of Ruptured Intracranial Aneurysms]. Pol Merkur Lekarski, 29, 217-221.

[16] Milantoni, N., Di Bella, N. and Chahbazian, K. (2018) Restoration of Balance and 
Unilateral Hearing Using Alternating and Filtering Auditory Training in Shunt-Treated Hydrocephalus Following Subarachnoid Hemorrhage: A Case Report. American Journal of Case Reports, 19, 935-940.

https://doi.org/10.12659/AJCR.909695

[17] De Luca, R., Lo Buono, V., Leo, A., Russo, M., Aragona, B., Leonardi, S., et al. (2019) Use of Virtual Reality in Improving Poststroke Neglect: Promising Neuropsychological and Neurophysiological Findings from a Case Study. Applied Neuropsychology: Adult, 26, 96-100. https://doi.org/10.1080/23279095.2017.1363040

[18] Blanz, M. and Koalick-Blanz, S. (1992) Effect of Combination Treatment by Concentration and Relaxation Training after Subarachnoid Hemorrhage (Single Case Analysis). Die Rehabilitation, 31, 246-253. https://doi.org/10.1016/S1474-4422(11)70108-9

[19] Macdonald, R.L., Higashida, R.T., Keller, E., Mayer, S.A., Molyneux, A., Raabe, A., et al. (2011) Clazosentan, an Endothelin Receptor Antagonist, in Patients with Aneurysmal Subarachnoid Haemorrhage Undergoing Surgical Clipping: A Randomised, Double-Blind, Placebo-Controlled Phase 3 Trial (Conscious-2). The Lancet Neurology, 10, 618-625. https://doi.org/10.1016/S1474-4422(11)70108-9

[20] Brooks, F.A., Ughwanogho, U., Henderson, G.V., Black-Schaffer, R., Sorond, F.A. and Tan, C.O. (2018) The Link Between Cerebrovascular Hemodynamics and Rehabilitation Outcomes after Aneurysmal Subarachnoid Hemorrhage. American Journal of Physical Medicine \& Rehabilitation, 97, 309-315. https://doi.org/10.1097/PHM.0000000000000886

[21] Wong, G.K.C., Lam, S.W., Wong, A., Ngai, K., Mok, V. and Poone, W.S. (2016) Early Cognitive Domain Deficits in Patients with Aneurysmal Subarachnoid Hemorrhage Correlate with Functional Status. Acta Neurochirurgica Supplement, 122, 129-132. https://doi.org/10.1007/978-3-319-22533-3_26

[22] Vergouwen, M.D., Vermeulen, M., Van Gijn, J., Rinkel, G.J., Wijdicks, E.F., Muizelaar, J.P., et al. (2010). Definition of Delayed Cerebral Ischemia after Aneurysmal Subarachnoid Hemorrhage as an Outcome Event in Clinical Trials and Observational Studies: Proposal of a Multidisciplinary Research Group. Stroke, 41, 2391-2395. https://doi.org/10.1161/STROKEAHA.110.589275

[23] Cockrell, J.R. and Folstein, M.F. (1988) Mini-Mental State Examination (MMSE). Psychopharmacology Bulletin, 24, 689-692.

[24] Fugl-Meyer, A.R., Jääskö, L., Leyman, I., Olsson, S. and Steglind, S. (1975) The Post-Stroke Hemiplegic Patient. A Method for Evaluation of Physical Performance. Scandinavian Journal of Rehabilitation Medicine, 7, 13-31.

[25] Williams, G. (2011) Functional Ambulation Classification. In: Kreutzer, J.S., Deluca, J. and Caplan, B., Eds., Encyclopedia of Clinical Neuropsychology, Springer, Cham. https://doi.org/10.1007/978-3-319-56782-2_1935-2

[26] Yuan, J.L., Wang, Y.X., Hu, W.L. and Bruno, A. (2020) The Reliability and Validity of a Novel Chinese Version Simplified Modified Rankin Scale Questionnaire.BMC Neurology, 20, Article No. 127. https://doi.org/10.1186/s12883-020-01708-1

[27] Quinn, T.J., Dawson, J., Walters, M.R. and Lees, K.R. (2009) Reliability of the Modified Rankin Scale: A Systematic Review. Stroke, 40, 3393-3395. https://doi.org/10.1161/STROKEAHA.109.557256

[28] Powers, D.W. (2001) Assessment of the Stroke Patient Using the NIH Stroke Scale. Emergency Medical Services, 30, 52-56.

[29] Spilker, J., Kongable, G., Barch, C., Braimah, J., Brattina, P., Daley, S., et al. (1997). Using the NIH Stroke Scale to Assess Stroke Patients. Journal of Neuroscience 
Nursing, 29, 384-392. https://doi.org/10.1097/01376517-199712000-00008

[30] Shah, S, Vanclay, F. and Cooper, B. (1989) Improving the Sensitivity of the Barthel Index for Stroke Rehabilitation. Journal of Clinical Epidemiology, 42, 703-709. https://doi.org/10.1016/0895-4356(89)90065-6

[31] Hocking, C., Williams, M., Broad, J. and Baskett, J. (1999) Sensitivity of Shah, Vanclay and Cooper's Modified Barthel Index. Clinical Rehabilitation, 13, 141-147. https://doi.org/10.1191/026921599668105029

[32] Mcmillan, T., Wilson, L., Ponsford, J., et al. (2016) The Glasgow Outcome Scale-40 Years of Application and Refinement. Nature Reviews Neurology, 12, 477-485. https://doi.org/10.1038/nrneurol.2016.89

[33] Wilson, J.T., Pettigrew, L.E., and Teasdale, G.M. (1998) Structured Interviews for the Glasgow Outcome Scale and the Extended Glasgow Outcome Scale: Guidelines for Their Use. Journal of Neurotrauma, 15, 573-585.

https://doi.org/10.1089/neu.1998.15.573

[34] Sano, H., Satoh, A., Murayama, Y., Kato, Y., Origasa, H., Inamasu, J., Nouri, M., Cherian, I., Saito, N. and Members of the 38 Registered Institutions and WFNS Cerebrovascular Disease \& Treatment Committee (2015) Modified World Federation of Neurosurgical Societies Subarachnoid Hemorrhage Grading System. World Neurosurgery, 83, 801-807. https://doi.org/10.1016/j.wneu.2014.12.032

[35] Rosen, D.S. and Macdonald, R.L. (2004) Grading of Subarachnoid Hemorrhage: Modification of the World Federation of Neurosurgical Societies Scale on the Basis of Data for A Large Series of Patients. Neurosurgery, 54, 566-575. https://doi.org/10.1227/01.NEU.0000108862.32404.A5

[36] Maeshima, S., Osawa, A., Yamane, F., et al. (2014) Memory Impairment Caused by Cerebral Hematoma in the Left Medial Temporal Lobe Due to Ruptured Posterior Cerebral Artery Aneurysm. BMC Neurology, 7, Article No. 44. https://doi.org/10.1186/1471-2377-14-44

[37] Kober, S.E., Schweiger, D., Reichert, J.L., Neuper, C. and Wood, G. (2017) Upper Alpha Based Neurofeedback Training in Chronic Stroke: Brain Plasticity Processes and Cognitive Effects. Applied Psychophysiology and Biofeedback, 42, 69-83. https://doi.org/10.1007/s10484-017-9353-5

[38] Chen, Z., Song, W.Q., Du, J.B., Li, G.Q., Yang, Y.H. and Ling, F. (2009) Rehabilitation Combined with Ventriculoperitoneal Shunt for Patients with Chronic Normal Pressure Hydrocephalus Due to Aneurysm Subarachnoid Haemorrhage: A Preliminary Study. Journal of Rehabilitation Medicine, 41, 1096-1099. https://doi.org/10.2340/16501977-0461

[39] Chen, Z., Song, W., Du, J., et al. (2009) Rehabilitation of Patients with Chronic Normal-Pressure Hydrocephalus after Aneurysmal Subarachnoid Hemorrhage Benefits from Ventriculoperitoneal Shunt. Topics in Stroke Rehabilitation, 16, 330-338.

https://doi.org/10.1310/tsr1605-330 